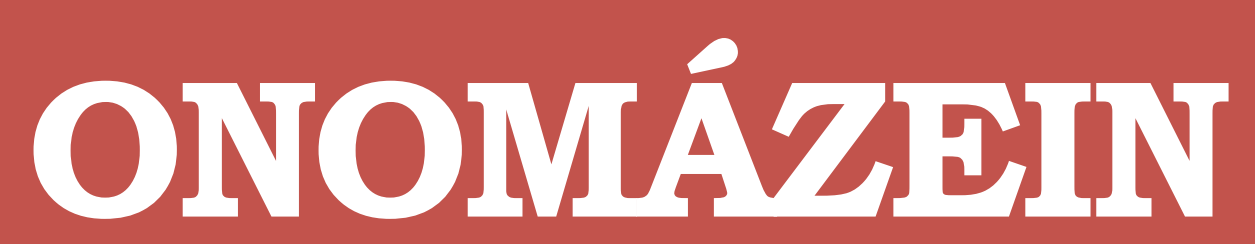

Revista de lingüística, filología y traducción
PONTIFICIA UNIVERSIDAD

\title{
Registro y evolución de la subcompetencia extralingüística en estudiantes de traducción
}

Record and evolution of the extralinguistic subcompetence in translation students

\section{José Cortez Godínez}

Universidad Autónoma de Baja California México

\section{(C) $($ (i) $\ominus$}

José Cortez Godínez: Facultad de Idiomas, Universidad Autónoma de Baja California, México. | E-mail: jose_cortez@uabc.edu.mx 


\section{Resumen}

Como parte del estudio empírico "Registro de la Competencia Traductora y Evaluación”" desarrollado en la Facultad de Idiomas - Campus Mexicali, de la Universidad Autónoma de Baja California, que analiza la traducción orientada al proceso, presentamos el presente artículo que aborda el estatus y evolución de la subcompetencia extralingüística(SE) en los grupos de traducción de nivel inicial y terminal. En la búsqueda de respuestas a la pregunta de trabajo del Grupo PACTE: ¿Cómo traducen los traductores? (PACTE, 2000, 2001, 2002, 2003, 2005, 2008, 2009, 2011), nos hemos dado a la tarea de analizar cómo se manifiestan las subcompetencias que integran su modelo holístico en la formación de los traductores.

Con el fin de evaluar la SE adaptamos una rúbrica de las guías de estudio establecidas por el Colegio de Bachilleres de Baja California (COBACH), de la Secretaría de Educación Pública (SEP) a nivel medio superior en México, por ser un conocimiento con el que todo universitario debe contar como requisito para ingresar a la Educación Superior. La importancia del estudio radica en que puede dar pistas sobre la "base de conocimiento" real de los discentes, para, a partir de allí, contrastarla con los contenidos de los planes y programas de estudio, que quedan a veces en el rezago, pues lo que antes era autodidactismo, en la era de los "Millennials" y la tecnología, se ve superado por el inmediatismo escolar.

Los resultados que arrojó la medición del llamado "conocimiento del mundo" en los estudiantes de traducción indican que 1) es un conocimiento que se mantiene en su bagaje desde su adquisición en el bachillerato; 2) su evolución del tercero al séptimo semestre abarca un rango de 72,91 a 80,09/100 en sus calificaciones, lo cual se puede interpretar como un avance de "regular" a "bueno"; y 3) esta evolución se incrementa en la etapa terminal de la carrera, donde el alumno practica la traducción especializada.

Palabras clave: subcompetencia extralingüística; competencia traductora; Grupo PACTE.

i Lainvestigación “Registro de la Competencia Traductora y Evaluación” (2018), con clave: 115/1659, fue registrada ante el Departamento de Posgrado e Investigación en Mexicali, Baja California, por parte de José Cortez Godínez, como responsable de la misma, en Universidad Autónoma de Baja California. 


\section{Abstract}

This research, that addresses the status and evolution of the extralinguistic subcompetence (ES) in the initial and final levels in the Bachelor's degree in Translation, is part of the empirical study “Translation Competence: Record \& Evaluation”. The study was developed in the Language School-Mexicali Campus, of the Autonomous University of Baja California, and analyzes the process-oriented translation. In the search for answers to the PACTE Group's question: How do translators translate? (PACTE, 1998, 2000, 2001, 2002, 2003, 2005, 2008, 2009, 2011), we have been analyzing how the subcompetences (that integrate their holistic model) work in the training of translators.

In order to assess the ES, we adapted a scale from the study guides established by the Colegio de Bachilleres de Baja California (Cobach, by its acronym in Spanish), regulated as a Prep School system in Mexico, by the Secretariat of Public Education (SEP). The questionnaire used encompasses a sample of knowledge with which every student must count as a requirement for admission to higher education. The importance of the study lies on the fact that it can shed some light on the real learner's knowledge base. Then, we could contrast it with the contents of the curricula, which remain sometimes in the lag. Something that worries us is that during this Millennium (The Age of Technology) the immediatism at school is surpassing the ancient self-learning; that is the main reason for doing this research.

The results yielded by the measurement of the so-called "general world knowledge" in translation students indicate that 1 ) it is a knowledge that is maintained in their memory since its acquisition in the baccalaureate; 2 ) its evolution from the third to the seventh semester covers a range of 72.91 to 80.09/100 in their marks, which can be interpreted as a step forward from "regular" to "good"; and 3) this evolution is incremented in the fourth year of the career, where the student practices specialised translation.

Keywords: extralinguistic subcompetence; translation competence; PACTE Group. 


\section{Introducción}

Antes de iniciar el desarrollo de este artículo, es importante exponer que antes del año 2013, en nuestra Facultad, los alumnos mayores de 21 años de edad, con mayor experiencia y conocimientos extralingüísticos, subsanaban sus fallos o deficiencias en las otras subcompetencias con ayuda de la subcompetencia estratégica y conocimientos en traducción (Cortez y otros, 2012). Es decir, eran traductores practicantes que no habían estado en las aulas de una facultad. Hoy día, los nuevos discentes son jóvenes que se dedican a estudiar, y algunos (mayormente en el turno vespertino) trabajan (no prioritariamente en traducción) y estudian. Lo mencionado tiene relación con la inquietud que nos impulsó a realizar el presente trabajo.

Con el fin de registrar el estado de las subcompetencias, y de poder realizar comparaciones con mediciones anteriores (Cortez y otros, 2013, 2015), se mantuvieron los mismos métodos y materiales aplicados en una investigación longitudinal (Cortez, 2014) de la competencia traductora (CT). Solo se implantó una rúbrica de tipo lingüístico-contrastivo (adaptado de Colina, 2009: 258), pero susceptible de convertirse a una escala de 0-100/100 como la utilizada en mediciones previas (ver anexo 1).

Para efectos del presente estudio, nos basaremos principalmente en la exploración y estatus de la subcompetencia extralingüística atendiendo los diferentes conceptos que se manejan para definirla tales como "conocimiento del mundo", "saber enciclopédico", el cual en su estado avanzado de especialización es Ilamado "conocimiento temático" (saber experto), sin ahondar ni abarcar el campo de la subcompetencia cultural (e intercultural), cuyo estudio y manejo ha tenido un repunte recientemente en los estudios de traducción.

De hecho, el modelo de Schäffner (2000: 146-147) define competencia cultural como "conocimiento general sobre aspectos históricos, políticos, económicos, culturales, etc., en sus respectivos países", mientras que otros autores califican este saber de enciclopédico.

\subsection{Formación de la subcompetencia extralingüística}

Dentro del plan de estudios ${ }^{1}$ de la Licenciatura en Traducción, existen materias que buscan ampliar el bagaje que forma la subcompetencia extralingüística del estudiante, tales como: Ética, Responsabilidad Social y Transparencia, Estructura Socioeconómica de México, Desarrollo del Mundo Contemporáneo, Formación de Emprendedores, Desarrollo de Habilidades del Pensamiento, Tópicos Selectos de Literatura, Literatura en la Lengua Inglesa,

1 Plan de Estudios de la Licenciatura en Traducción. Disponible en http://www.uabc.mx/formacionbasica/FichasPE/Lic_en_Traduccion.pdf. 
Grandes Figuras de la Literatura Hispanoamericana, Etimologías Grecolatinas, que pueden ser seleccionadas y cursadas durante cinco semestres, en 64 horas por semestre cada una, antes de llegar a la etapa terminal (sexto, séptimo y octavo), donde las materias optativas a escoger son Traducción Técnica, Científica, Jurídica, Multimedia, y/o Interpretación Social, Interpretación ante los Tribunales, entre otras, con el fin de especializarse en alguna área de la profesión.

Con nuestro sondeo o "fotografía" de la SE realizada durante el semestre 2017-2, buscamos conocer en primer lugar su estatus: cómo se encuentra en el inicio de la licenciatura: tercer semestre (los primeros dos semestres de la carrera implican la homologación de conocimientos en la lengua materna y el idioma inglés).

En segundo lugar, buscamos registrar si existe alguna influencia o paralelismo con las otras subcompetencias, como la subcompetencia de transferencia (SCTR) y la subcompetencia lingüística en L2 (SLL2) en la etapa terminal (en este caso, séptimo semestre).

Por último, buscamos realizar un comparativo del estado de la SE en los estudiantes de tercer semestre, previo a su inserción a la carrera², con los estudiantes próximos a egresar (séptimo).

Cabe aclarar que el instrumento aplicado (anexo 5 b) es una adaptación y abarca una selección (100 preguntas) de entre los conocimientos generales estándares que todo preparatoriano debe llevar antes de su inserción en la educación superior, y abarca las áreas de lectura y redacción, literatura, historia de México y universal, salud y biología, ecología, química, estructura socioeconómica y métodos de investigación.

Cabe recordar que la subcompetencia extralingüística conlleva un orden lógico de desarrollo. Comienza con el "conocimiento general del mundo", que puede ser directo o triangulado, por ejemplo, desde que somos pequeños y cuando nuestros padres nos dicen que no metamos alambres al tomacorriente (memoria episódica) o saber el año en que se descubrió el Nuevo Mundo (memoria semántica); en el área de quienes utilizamos los idiomas como herramienta, implica además un "conocimiento bicultural”; finalmente, en el camino a ser experto, al igual que otros profesionales, implica el "conocimiento de un dominio específico" (especialización).

Como afirma Quezada (2004: 114), "un traductor debe leer y comprender todo, o de lo contrario se arriesga a cometer errores graves. [...] (El traductor) se encuentra en una situación en la que hipotéticamente puede establecer un muy amplio abanico de inferencias".

2 Las técnicas de traducción se imparten en tercer semestre. 
Existe el clisé de que el traductor debe ser una "biblioteca ambulante"; quizá es algo exagerado, pero lo que sí es cierto es que debe estar al tanto del mundo que nos rodea y saber un poco de todo. Lo que es más importante, debe saber cómo resolver problemas de información rápido y de manera efectiva. Por tanto, un "conocimiento enciclopédico" en este caso no significa recitar memorísticamente libros completos, sino resolver problemas de documentación, terminología, información o informática, relacionada con un proyecto de traducción específico, o al menos saber dónde buscarla.

\section{El modelo PACTE}

Retomando las ideas de Bell (1991: 39) y su postura sobre el "modelo del traductor ideal", el mismo recomienda que se debería adoptar "un enfoque menos abstracto y describir la competencia traductora en términos de generalizaciones basadas en inferencias extraídas de la observación del desempeño del traductor".

Asimismo, para llevar a cabo el análisis y plantear el estado de la subcompetencia extralingüística, el de la SCTR y la SLL2 o lengua a traducir, citamos el concepto de competencia traductora formulado por Kelly (2002: 9), quien la define como

... el conjunto de capacidades, destrezas, conocimientos e incluso actitudes que reúnen los traductores profesionales y que intervienen en la traducción como actividad experta, es decir que, en su conjunto, distinguen al profesional del no profesional, al experto del no experto, o del "native translator" [traductor nativo] de Toury (1984).

Como hemos mencionado anteriormente, nos interesan especialmente las subcompetencias en las que se divide la competencia traductora, establecidas por el Grupo PACTE (2002: 127):

1. Competencia lingüística en dos lenguas. Competencia gramatical, textual, ilocutiva, sociolingüística.

2. Competencia extralingüística. Conocimientos acerca de la organización del mundo en general y de ámbitos particulares: conocimientos biculturales, enciclopédicos, temáticos y sobre la traducción.

3. Competencia instrumental/profesional. Conocimientos y habilidades relacionados con el ejercicio de la traducción profesional: conocimiento del mercado laboral y comportamiento del traductor profesional, conocimiento y uso de las fuentes de documentación de todo tipo y de las nuevas tecnologías necesarias para el traductor.

4. Competencia psicofisiológica. Habilidad de aplicación de recursos psicomotores, cognitivos y actitudinales.

5. Competencia de transferencia. Capacidad de recorrer el proceso de transferencia desde el texto original hasta la elaboración del texto final. 
6. Competencia estratégica. Procedimientos conscientes e inconscientes, verbales y no verbales, utilizados para resolver los problemas encontrados en el desarrollo del proceso traductor.

Más recientemente, Hurtado y Alves (2009: 63, en Moura y Fernandes, 2016: 15) han dicho que la competencia traductora también es conocida "... como capacidad de traducción, habilidades de traducción, competencia traslativa, competencia del traductor y experiencia en traducción”.

En el caso del modelo constructivista de Kiraly (2000), el desarrollo del proceso traductor requiere la intervención de conocimientos lingüísticos (de las dos lenguas en cuestión), así como conocimientos extralingüísticos: saber enciclopédico, conocimiento temático, conocimientos culturales, conocimiento sobre las circunstancias que rodean la traducción concreta (contexto del TO, contexto de realización de la traducción, de las especificaciones de la tarea traductora, etc.).

El autor advierte a los profesores de traducción que "las normas de traducción difieren de cultura a cultura y evolucionan con el tiempo...”, y sobre la especialización de los alumnos señala: "Los estudiantes pueden elegir un área especial en la cual volverse expertos durante sus estudios y, sin embargo, ser atraídos por las circunstancias a áreas de traducción radicalmente diferentes en el transcurso de sus carreras" (2000: 13). De ahí la necesidad de la "educación a lo largo de la vida" y de que los sujetos tengan bases sólidas en su "conocimiento del mundo".

Por otro lado, Wilss (1976: 120, en Kelly, 2002: 11) propone tres competencias, en una temprana descripción de la competencia traductora con fines de diseño curricular:

a) Una competencia receptiva en el idioma fuente (la capacidad de decodificar y comprender el texto fuente).

b) Una competencia productiva en el idioma de destino (la capacidad de utilizar los recursos lingüísticos y textuales del idioma de destino).

c) Una supercompetencia, básicamente definida como la capacidad de transferir mensajes entre los sistemas lingüísticos y textuales de la cultura de origen y los sistemas lingüísticos y textuales de la cultura de destino.

Como podemos observar, la SE queda implícita en el inciso C, pues el traductor debe tener ciertas habilidades y destrezas, y estos conocimientos, habilidades y destrezas son necesarios para poder desarrollar correctamente el proceso traductor, es decir, realizar la transferencia del texto de una LI a una L2.

Sobre la subcompetencia de transferencia, sin nombrarla como tal, Hatim (2001: 23, en Nida y Taber, 1969: 33) habla de la etapa de transferencia como aquella "en la que el material analizado se transfiere en la mente del traductor del idioma A al idioma B", y resalta la importancia del contexto y los ajustes de elementos semánticos durante el proceso de translación. 


\subsection{SE y sus cruces}

A lo largo de la carrera, el alumno desarrolla sus competencias investigativas y terminológicas apoyado por la tecnología y la documentación en línea en su búsqueda de textos paralelos o información que lo apoye en el manejo del discurso y la textualidad de algún proyecto de traducción.

Por eso consideramos importante sondear los saberes que activan los sujetos en su "base de conocimiento", los recursos con los que cuentan y con los que harán frente, en el día a día, a cada proyecto de traducción. En suma, lo que será su conocimiento enciclopédico en ciernes, una vez que egresen, se enfrenten a problemas y tomen decisiones (por ejemplo, en el proceso de documentación o en el programa de traducción asistida que vayan a usar, y que les facilite lidiar con el encargo). Ahí radica la importancia de los saberes que los estudiantes deben tener, no como una simple acumulación memorística, sino como información que active sus búsquedas y los lleve a resolver problemas.

En cada proyecto, los alumnos deben de manejar un discurso, el cual lo define Van Dijk (2012: 178) "como cualquier forma de uso del lenguaje manifestada en textos (escritos) o interacciones (habladas) en un sentido semiótico amplio" (incluida la comunicación multimedia). Sabemos que hoy en día, la información (de buena y mala calidad) está al alcance de un botón, por lo que esto permite al discente el acceso a revistas especializadas en traducción y lingüística, así como bases de datos que pueden apoyarlo en su gestión terminológica. Es decir, la fase que abarca la documentación y la gestión terminológica puntual es casi inmediata, sin necesidad de trasladarse amplias distancias, como antaño.

En esta formación del estudiante de traducción se busca que las materias ofertadas a lo largo del grado permitan el mayor desarrollo de su saber enciclopédico y analítico para, al menos, saber dónde encontrar la información necesaria, con el fin de sacar adelante un proyecto de trabajo: fuentes bibliográficas, electrónicas, hemerográficas, videográficas y vivas.

El papel del docente/facilitador, por tanto, es fomentar la adquisición de la subcompetencia extralingüística (conocimiento experto) e instrumental (documentación³) en el aula (Barceló y Delgado, 2017: 39).

De acuerdo a estudiosos sobre el desarrollo de la lengua, "una lectura amplia no sólo aumenta el conocimiento del significado de la palabra, sino que también puede producir avances en el conocimiento temático y del mundo, que pueden facilitar aún más la comprensión de la lectura" (Harris y Sipay, 1990: 533).

3 Nosotros agregaríamos: búsqueda eficiente de información en línea, portales de traducción, glosarios de acceso libre, sitios de instituciones y universidades, blogs, wikis, etc., como recursos de apoyo a la documentación. 
La lectoescritura es una herramienta de trabajo importante del traductor y su forma de aprehender/aprender el mundo diariamente (además de las otras sensaciones que alimentan la memoria operativa), por lo que la SE no es la excepción en este proceso de adquisición de estímulos. Lo mismo aprende el sujeto en un viaje virtual al Museo de Antropología e Historia de la Ciudad de México que leyendo un libro de la historia del arte. Todos los estímulos son codificados y almacenados de acuerdo a su relevancia e importancia futura para el sujeto.

\subsection{Adquisición de la SE}

Antes de alcanzar el conocimiento experto, los estudiantes novatos traen un nivel mínimo de "conocimiento del mundo", que adquirieron a lo largo de su formación desde preescolar hasta la escuela preparatoria (nivel medio superior), amén de sus intereses personales por su propio desarrollo cultural personal. Empezar por conocer lo anterior daría un punto de partida en la medición de la efectividad de los planes y programas de estudio, sin tener que esperar cinco años para que se ajusten los contenidos.

A su ingreso a la Facultad, los estudiantes reciben un curso propedéutico para actualizar sus conocimientos en el idioma inglés, pues su nivel de manejo del idioma no es homogéneo. Existen casos, por nuestra vecindad con EE. UU., en que su lengua materna es el inglés y su lengua a traducir es el español. Ante esto, se espera que los estudiantes al egresar sean expertos en traducción o interpretación, y en un área de especialidad que sea de su preferencia, lo cual permite la flexibilidad curricular.

Con relación al concepto, el Grupo PACTE (2003: 58) afirma que la subcompetencia extralingüística es un conocimiento "predominantemente declarativo, tanto implícito como explícito, sobre el mundo en general y áreas especiales. Incluye: (1) conocimiento bicultural (sobre las culturas de origen y destino); (2) conocimiento enciclopédico (sobre el mundo en general); (3) conocimiento del tema (en áreas especiales)".

Cabe aclarar que en nuestra Facultad no se mide la subcompetencia lingüística en Lı (lengua materna) con algún examen internacional como el DELE (Diplomas de Español como Lengua Extranjera) o el SICELE (Sistema Internacional de Certificación del Español como Lengua Extranjera), pues se da por sentado el dominio de la cultura en Lı. Tampoco se conocen los saberes mínimos que integran la subcompetencia extralingüística. De allí la pertinencia de saber cómo viene integrada la SE en los que inician su formación en traducción, pues sobre esa base, y a partir de la etapa terminal de la carrera (sexto, séptimo y octavo), los sujetos se especializarán en dominios como traducción jurídica, científica, comercial, técnica, entre otras; o si se decantan por interpretación, serían interpretación de enlace, interpretación ante los tribunales, social, etc.

Es pertinente aclarar que no quedan muy claros los límites, difusos de suyo, entre la llamada competencia cultural y el conocimiento del mundo / saber enciclopédico con el que 
debe de contar un joven, en una edad promedio de 21 años, que cursa la carrera universitaria que nos ocupa. De ahí nuestro interés por el tema.

\subsection{Conocimiento y su manejo}

Con el fin de dar algo de luz al concepto "conocimiento del mundo" — también conocido como conocimiento enciclopédico - recurrimos a la teoría de Ausubel, Novak y Hanesian (1968), la cual explica que el proceso de aprendizaje cognitivo se preocupa de los procesos de comprensión, transformación, almacenamiento y uso de la información envueltos en el proceso cognitivo.

Dicho enfoque constructivista considera a la ciencia como algo dinámico, no estático, basado en la creencia de que nosotros estructuramos nuestro mundo a través de las percepciones de nuestras experiencias, de nuestros sentidos. Según esta teoría, el conocimiento es considerado como flexible y evoluciona basado en nuevos hallazgos donde lo nuevo busca su acomodo entre las experiencias previas, sean directas o trianguladas. Además, el constructo previo sirve como referente para la inclusión de los nuevos conocimientos (considerados relevantes por el sujeto) y que formarán parte de su memoria a largo plazo, y finalmente de su bagaje con el cual enfrenta el mundo.

Para Ausubel y otros (1968) nuevas ideas e informaciones pueden ser aprendidas y retenidas en la medida en que conceptos relevantes o adecuados e inclusivos se encuentren apropiadamente claros y disponibles en la estructura cognitiva del individuo y sirvan, de esta forma, de anclaje a nuevas ideas y conceptos en la información que una persona tiene almacenada en su memoria a partir de lo que ha experimentado o vivido.

El interés por el conocimiento del mundo como objeto de estudio nace a partir de la segunda mitad del siglo pasado en la psicología cognitiva, interesada por conocer de qué modo la mente humana procesa y almacena la información para realizar aprendizajes significativos. "Por tanto, a partir de la edad escolar, la asimilación es el proceso fundamental de la adquisición de significados" (Pozo, 2006: 217).

Esta conceptualización de "conocimiento del mundo" también ha sido integrada al análisis del discurso para dar cuenta de cómo se lleva a cabo su interpretación. Van Dijk (1980: 80) nos dice que el "... usuario de una lengua construirá una estructura conceptual mediante el uso de elementos tomados de la memoria (conocimiento de la lengua y del mundo, almacenado en MLP4, que por lo tanto se llama también nuestra memoria semántica o conceptual”. Los interlocutores deben compartir cierto conocimiento del mundo para poder interpretar un discurso como coherente. En ocasiones, un discurso puede resultar incoherente para un

4 Memoria a largo plazo. 
destinatario porque carece del conocimiento del mundo necesario (relevante) para comprender acertadamente dicho mensaje.

Van Dijk (1980: 101) lo plantea como sigue: "Para comprender el procesamiento cognoscitivo más complejo, es necesario primero subrayar que todos estos procesos dependen de los sistemas de conocimientos y creencias del individuo. Componen el 'banco de datos y creencias' del individuo".

Por otro lado, Meersohn (2005) sobre conocimiento del mundo y discurso expone que

la forma en que comprendemos los significados de los hechos y en que adquirimos y procesamos la información y conocimiento del mundo que poseemos no depende sólo de las operaciones semánticas realizadas al producir, escuchar o comprender un acto discursivo, sino que estas mismas operaciones están a su vez ligadas a otras operaciones de orden cognitivo, mediante las cuales organizamos mentalmente dicha información y los significados que le atribuimos. Estas operaciones de orden cognitivo, recordemos, estarían formando parte de la tríada psico-socio-lingüística, de la cual extraemos los elementos para un análisis interdisciplinario del discurso.

Nuestro concepto de "conocimiento del mundo" está además relacionado con "conocimiento social" o "cognición social” (social cognition), que estudia el pensamiento sobre objetos sociales, vinculándolo con los cambios en las capacidades cognitivas en general, y mostrando que los aspectos sociales están muy relacionados con las capacidades cognitivas en su conjunto.

Paricio (2014: 221) por su parte dice que el conocimiento del mundo incluye a) lugares, instituciones y organizaciones, personas, acontecimientos, objetos e intervenciones en distintos ámbitos; es de especial importancia para el alumnado el conocimiento factual del país donde se habla el idioma objeto de aprendizaje...; b) clases de entidades (concretas, abstractas, animadas e inanimadas, etc.) y sus propiedades y relaciones.

Si se quiere ver de manera más simplista, aunque sea solo una convención para captar la realidad: el hombre rodeado de un entorno social, donde codifica los eventos, las acciones, sus cualidades, sus intensificadores y conectores (sustantivos, verbos, adjetivos, adverbios y determinantes).

\subsection{Competencia cultural}

Como dijimos anteriormente, es difícil delimitar hasta dónde el conocimiento que traen los sujetos es "enciclopédico" o "cultural", pues algunos autores consideran a la cultura como toda manifestación humana.

Por ejemplo, para Chinoy (2002 [1960]: 41) es el modo de vida de un grupo “... incluyendo los sistemas de creencia, conocimiento, valores, modos de acción física, y sentimientos o 
afectos pautados; así como las reglas de conducta son compartidas por todos los hombres, son adquiridas antes que innatas e instintivas".

Martínez, Martínez y Calzado (2006) describen cultura y competencia de la siguiente forma:

En sentido amplio la cultura puede ser entendida como el patrón integrado de conductas humanas - pensamientos, comunicación, prácticas, costumbres, creencias, valores, instituciones, etc.- de grupos específicos definidos por dimensiones como la etnia, género, nacionalidad, estatus socioeconómico, opción sexual, religiosa o política, etc. Por su parte, la competencia se refiere, con carácter general, a la habilidad para funcionar eficazmente.

Por tanto, los autores citados definen competencia cultural "como el conjunto de conocimientos, actitudes, conductas, y en su caso políticas y programas, que confluyen en una persona, organismo o sistema que le capacitan para trabajar (convivir, ser implementado, etc.) con eficacia en contextos interculturales" (334).

En el campo académico, Hurtado (2001: 607) nos indica que la traducción “... no sólo se produce entre dos lenguas diferentes, sino también entre dos culturas diferentes; [...] es [...] una comunicación intercultural. El trasvase de los elementos culturales presentes en un texto es uno de los mayores problemas a que se enfrenta el traductor".

Además, la traductóloga (368) menciona que autores como Seleskovitch y Lederer, Bell, Kiraly, etc., inciden en el papel de la memoria (a corto y a largo plazo) y del saber lingüístico y extralingüístico almacenado por ella en todos los procesos involucrados en la traducción.

En el mismo sentido (PACTE, 2002: 127), agrega que en el ámbito de la traducción este conocimiento debe ser bilingüe y bicultural.

\subsection{Conocimiento especializado}

En su camino hacia convertirse en expertos, los estudiantes emprenden un viaje de adquisición de conocimientos, que, en el caso de la traducción, es para toda la vida. Conocer aunque sea de manera parcial el estatus de ese "almacén” quizá nos revele pistas de cómo se integra antes de su especialización.

De acuerdo con Barceló y Delgado (2017: 43), el "conocimiento experto [...] es el conjunto de saberes propios de una disciplina indispensables para la correcta comprensión de un texto de dicha especialidad".

Los autores además externan que, en el área de la traducción jurídica, verbigracia, para "adquirir la subcompetencia extralingüística resulta indispensable abordar aspectos como 
la necesidad de contar con un conocimiento experto solvente, las implicaciones traductoras de los anisomorfismos ${ }^{5}$ culturales y la intertextualidad, entre otros".

Con respecto a la profundidad de dichos conocimientos que el traductor debe alcanzar en el grado, Mayoral Asensio (1997: 142-143) plantea que

... el nivel de comprensión suficiente para la traducción especializada [...] se acerca más al concepto de comprensión pasiva (comprensión del hecho por sí mismo, sin integrarlo en el conocimiento general del mismo que posee el traductor) que al concepto de comprensión activa.

Además, Gile (1995: 86) afirma que “... muchos clientes, e incluso algunos profesionales de la traducción, sienten que los traductores sólo pueden efectuar un trabajo decente en áreas que ellos conozcan tan bien - o casi tan bien-como los especialistas".

Ante esto, también es lógico considerar que los estudiantes que poseen conocimientos sobre el campo o disciplina que están traduciendo, a menudo entienden mejor lo que están leyendo que los que tienen poco conocimiento sobre el tema. Ahí radica la importancia de la documentación, la gestión terminológica adecuada y un amplio "conocimiento del mundo".

El “conocimiento del mundo" permite hacer conexiones rápidas entre contenidos nuevos con los almacenados previamente en la memoria semántica y en la representacional. Aquel, al igual que el conocimiento temático (especializado), permite al traductor no experto en derecho, por ejemplo, darles sentido a las combinaciones de palabras y términos en la traducción jurídica, y cumplir con los proyectos (Valderrey, 2005). Además, el conocimiento "pasivo" al que alude Valderrey permite elegir entre varios significados posibles, hacer conexiones con todo el texto (textualidad holística) y realizar inferencias. La autora, sobre los requerimientos de los novatos en traducción en el área jurídica, afirma (8): "Sin duda alguna, ambos adjetivos, 'pasivo' y ‘utilitario', permiten una primera y certera aproximación a la naturaleza del conocimiento temático requerido para traducir textos jurídicos”.

Si los sujetos son capaces de acceder a su "conocimiento del mundo" de manera efectiva y adecuada, son más propensos a relacionar lo que saben con los textos que están leyendo. Vital para la comprensión de un texto es el conocimiento que el traductor lleva consigo, el solo conocimiento del idioma no es suficiente.

En resumen, para efectos de nuestro estudio, la subcompetencia extralingüística sería el "conocimiento del mundo" que traen en su memoria los estudiantes de la Licenciatura en Traducción y que les permitió ingresar al grado superior. Este "cuerpo de conocimientos

5 El término anisomorfismo está vinculado a un concepto muy manido en el campo de la traducción y la traductología: Ia intraducibilidad (Alcaraz: 202). Las palabras del traductor. En Centro Virtual Cervantes. Disponible en https://cvc.cervantes.es/lengua/esletra/pdf/02/021_alcaraz.pdf. 
primario" crecerá y se especializará hasta llegar a ser un "genuino cuerpo de conocimientos" necesarios para ejercer la profesión (a su egreso). Hasta aquí las conceptualizaciones de la subcompetencia extralingüística.

\section{Métodos y materiales}

La muestra extraída del tercer semestre está compuesta por 24 de 27 alumnos que cursaron el periodo lectivo de agosto de 2017 / enero de 2018 y que comprende el semestre 2017-2.

El examen de conocimientos (anexo 5 y anexo 5 b) para la medición de la SE es un baremo adaptado (100 preguntas) de las guías de estudio establecidas por el Ilamado Colegio de Bachilleres de Baja California, de la Secretaría de Educación Pública(SEP) a nivel medio superior en México ${ }^{6}$.

Por su parte, las muestras de los dos grupos de séptimo representan: en el matutino el $70,58 \%$ y en el vespertino el $76,92 \%$ de cada universo individual, por lo que los resultados se pueden generalizar a ambos grupos. Si se tomara como un solo universo, la muestra representa el 75,86\% de los dos grupos de séptimo semestre de la Facultad de Idiomas - Campus Mexicali.

Con el fin de mantener la replicabilidad, el examen se imprimió en papel para su aplicación en los grupos de tercero y séptimo (matutino y vespertino)?. Es de tomarse en cuenta que el grupo de tercer semestre tiene los conocimientos más recientes a medir que los sujetos próximos a egresar de la carrera, los cuales se hallan inmersos en proyectos de traducción de todo tipo y especializados. Antes del experimento, el cuestionario se probó con un grupo de cuatro alumnos de quinto semestre, quienes fungieron como grupo piloto. Tras sus comentarios se corrigió el instrumento.

Dentro de los programas utilizados para registrar la SCTR se encuentra Translog2000/Translog200user. Aunque las versiones de Translog se han ido actualizando hasta 2006, ahora su heredero es Translog-II. Sobre la nueva versión del software, la página web explica lo siguiente:

Translog-1/8 es un programa para grabar y estudiar los procesos de lectoescritura hechos en una computadora [...]. Es un instrumento para obtener datos digitales objetivos del proceso de traducción humana. Como sus predecesores, Translog 2000 y Translog 2006, también Translog-II consiste en dos principales componentes: Translog-II Supervisor es usado para crear un archivo proyecto

6 Guías de estudio del Colegio de Bachilleres de Baja California. Disponible en http://alumnos.cobachbc.edu.mx/parciales/.

7 Disponible en https://drive.google.com/drive/u/l/search?ogsrc=32\&q=examen\%20SE previo envío de correo electrónico.

8 Sitio web donde se puede adquirir el programa informático: Centro de Investigación e Innovación en Traducción y Tecnología en Traducción, disponible en https://sites.google.com/site/centretranslationinnovation/translog-ii. 
y reproducir las sesiones grabadas. Translog-II User es utilizado para grabar los experimentos de producción de un texto (mientras el usuario lee, escribe y traduce el texto). Translog-II produce archivos bitácora que contienen los datos de la actividad del usuario de una lectura, escritura y del proceso de traducción, el cual puede ser evaluado por medio de herramientas externas9.

Otros programas informáticos utilizados en el experimento fueron Word y Excel de Office 2016. El texto utilizado para la medición de la SCTR fue una traducción del inglés al español, de 412 palabras sobre el tema de la miopía (texto informativo-científico tomado de la Internet) convertido a extensión tp/ para su traducción dentro del programa Translog200ouser por los estudiantes (ver anexo 7). El programa produce un texto-bitácora, con extensión log, para ser analizado en Translog2000 por el investigador y convertido finalmente a rtf (Word) para su posterior revisión y calificación por dos profesores de la Facultad con más de cinco años de experiencia (con un código para evitar sesgos) y dos alumnos de octavo semestre (ver anexo 7 b).

Sobre los archivos tipo log, Hansen (2003: 36) nos dice:

... el investigador tiene la posibilidad de observar el proceso de escritura en un archivo de registro log., que muestra todas las frases y pausas. Los datos del archivo de registro son una observación objetiva en tercera persona, pero la evaluación de los resultados de los movimientos después de las pausas no lo son. Por esta razón, es necesario interpretarlos y debatirlos.

El experimento tiene un lapso de 1 hora 40 minutos, de una clase de dos horas, con el fin de medir la subcompetencia de transferencia (esencia de la competencia traductora) de los estudiantes. Cabe agregar que las sesiones siempre tuvieron el mismo lapso y se realizaron en el Laboratorio de Traducción de la Facultad de Idiomas - Campus Mexicali. Para registrar la subcompetecia psicofisiológica, se aplicaron dos cuestionarios: uno pretarea y otro postarea de traducción.

Los sujetos estudiados, durante el semestre 2017-2, fueron los estudiantes de III y VII semestres. La metodología o proceso para la medición de la SCTR fue el Protocolo Previo de Traducción (PPT), que “... es un protocolo que puede servir de andamiaje en el constructo del estudiante de traducción novato” (Cortez, 2014: 121) (ver anexo 6).

\section{Resultados y discusión}

\subsection{Tercer semestre}

El grupo está integrado por 27 estudiantes (ver tabla 1) que inician el estudio de las materias de traducción, donde el 33,33\% está integrado por varones y el resto por mujeres. La media de la SE es 72,91 de calificación.

9 La traducción es nuestra. 
Con relación al estado y la existencia de la SE en los novatos en traducción podemos externar que se encuentra en un promedio de regular a buena, tomando en cuenta la escala de nuestra universidad para evaluar a su población estudiantil: el baremo utilizado por los correctores/revisores fue de o a 100/100 y registra si el alumno puede evocar los conocimientos que adquirió un año y medio antes de su ingreso a la educación superior.

También se utilizó el mismo baremo para medir el rendimiento de los estudiantes en el Pre-Toefl (SLL2) y la SCTR. La escala se encuentra regulada en el estatuto escolar de la UABC ${ }^{10}$, artículo 65.

Así vemos que una calificación "excelente" de un sujeto sería 100/100; el resultado "muy bueno" de una variable medida sería de 90-99/100; "bueno", de 80-89/100; "regular", de 7079/100; "suficiente", 60-69/100, e "insuficiente" o "suspenso", 59/100 o menor.

\section{TABLA 1}

Representación de la subcompetencia extralingüística del tercer semestre de Licenciatura en Traducción, con la puntuación mostrada de mayor a menor y por sexo. Fuente: elaborada con datos propios

\begin{tabular}{|c|c|c|c|c|c|c|c|}
\hline SUJETO & SEXO & SE & CÓDIGO & SUJETO & SEXO & SE & CÓDIGO \\
\hline 1 & HOMBRE & 89 & PRJA & 13 & MUJER & 72 & SBL \\
\hline 2 & MUJER & 86 & PFLI & 14 & MUJER & 72 & PPPD \\
\hline 3 & MUJER & 81 & RLSG & 15 & MUJER & 71 & GCML \\
\hline 4 & MUJER & 81 & AMP & 16 & MUJER & 70 & YHC \\
\hline 5 & MUJER & 79 & SRMA & 17 & MUJER & 70 & GLC \\
\hline 6 & HOMBRE & 77 & EVM & 18 & HOMBRE & 68 & ZSE \\
\hline 7 & HOMBRE & 76 & CNC & 19 & MUJER & 68 & FAA \\
\hline 8 & MUJER & 75 & AVMA & 20 & MUJER & 68 & CPM \\
\hline 9 & MUJER & 74 & RMM & 21 & MUJER & 67 & PRA \\
\hline 10 & HOMBRE & 74 & LVMA & 22 & MUJER & 64 & SGA \\
\hline 11 & MUJER & 74 & BRVA & 23 & HOMBRE & 63 & $\mathrm{HDI}$ \\
\hline 12 & HOMBRE & 73 & VMCE & 24 & MUJER & 58 & MVK \\
\hline Promedio & H: $25 \%$ M: $75 \%$ & $72,91 / 100$ & & & & & \\
\hline
\end{tabular}

10 Sitio web del estatuto escolar de la UABC. Recuperado de http://sriagral.uabc.mx/Externos/AbogadoGeneral/Reglamentos/Estatutos/03_EstatutoEscolarUABC_ReformasDic2015.pdf. 


\subsection{Grupos de séptimo semestre}

La muestra del séptimo semestre matutino de Licenciado en Traducción está compuesta por doce sujetos, de un grupo de 17 , que se sometieron a la medición de la SE, lo que equivale al 70,58\% del universo medido. Además, la muestra está compuesta por dos hombres y diez mujeres. Sin embargo, solo diez sujetos fueron examinados en las tres variables: subcompetencia de transferencia, subcompetencia lingüística en L2 y subcompetencia extralingüística, lo que nos da el 58,82\% de la población, que sigue siendo representativo.

Por su parte, el séptimo semestre vespertino consta de 13 alumnos, de los cuales ocho reunieron los requisitos de elegibilidad (realizaron todas las pruebas), que es un $61,53 \%$.

Dentro de los resultados de la subcompetencia de transferencia (SCTR), un sujeto fue excluido, pues, aunque realizó la traducción, no salvó el archivo-bitácora en Translog200ouser. El promedio general del grupo vespertino fue de 95.77/100.

La conformación de dicha muestra por sexo es de siete mujeres y cuatro hombres. Las dos calificaciones más altas (100/100) fueron de un hombre y una mujer. La tercera más alta, 98.21/100, fue alcanzada por dos mujeres y un hombre. Grosso modo, el grupo fue el más sobresaliente de los tres.

Las matrices utilizadas para el contraste son:

1. SE de tercer semestre (anexo 2).

2. SE en séptimo semestre matutino (anexo 3).

3. SE en séptimo semestre vespertino (anexo 4).

Como dato curioso y en abono (y descargo) a la capacidad del varón para concentrarse en una sola actividad y a su visualización espacio-temporal-matemática, de acuerdo a la neurolingüística, vemos que en las máximas calificaciones existe presencia masculina (tercero y séptimo vespertino), a pesar de la abrumadora mayoría del sexo femenino, que desde 2006 a 2013 (Cortez, 2014: 246) ha triplicado su presencia en las aulas de Traducción. En esta medición los porcentajes fueron los siguientes: tercer semestre (hombres: $25 \%$, mujeres: $75 \%$ ); séptimo matutino (hombres: $11,76 \%$, mujeres: $88,24 \%$ ), y séptimo vespertino: (hombres: 30,76\%, mujeres: 69,24\%).

\subsection{Grupo de séptimo matutino}

El séptimo semestre matutino (ver tabla 2) mostró una SE en un nivel "regular" en cuanto al conocimiento adquirido en la escuela preparatoria. 
En nuestra andadura del estudio de la CT que se inició en 2006, creímos importante establecer parámetros (Cortez, 2014: 175) para poder medir los avances en el desarrollo de las subcompetencias que van adquiriendo los estudiantes en el curso de sus estudios, por lo que nuestro baremo para registrar el equilibrio/desequilibrio entre la SCTR y la SLL2 (y ahora la SE) fue de 15/100 puntos porcentuales (más o menos) entre ellas, para considerarlas en equilibrio. Por lo que, si un sujeto presenta una SCTR de 90/100 y un SLL2 de 60/100, nos dice que hay un desbalance entre una y otra.

\section{TABLA 2}

La tabla muestra el comparativo entre las tres variables medidas en el séptimo semestre matutino, donde hay un balance visible entre ellas. Fuente: con datos propios

\begin{tabular}{|c|c|c|c|c|c|}
\hline SUJETO & & SCTR & SLL2 & SE & CÓDIGO/NOMBRE \\
\hline 1 & MUJER & 87 & 86 & 85 & VGEN \\
\hline 2 & MUJER & 87 & 83 & 82 & JPMF \\
\hline 3 & MUJER & 87 & 86 & 81 & $\mathrm{AOA}$ \\
\hline 4 & MUJER & NP & NP & 80 & NPM \\
\hline 5 & MUJER & 86 & 82 & 79 & FMAI \\
\hline 6 & MUJER & 86 & 82 & 72 & CLMF \\
\hline 7 & MUJER & NP & 74 & 70 & BVLD \\
\hline 8 & HOMBRE & 77 & 65 & 68 & IGHR \\
\hline 9 & MUJER & 83 & 58 & 65 & TCAG \\
\hline 10 & MUJER & 84 & 59 & 61 & ZLME \\
\hline 11 & HOMBRE & 82 & NP & & ZMJF \\
\hline 12 & MUJER & 80 & 42 & & RRVY \\
\hline 13 & MUJER & 87 & 78 & & CGK \\
\hline 14 & MUJER & 84 & 76 & 88 & DZJG \\
\hline 15 & MUJER & 83 & 69 & 68 & FLP \\
\hline 16 & MUJER & NP & 76 & & ESM \\
\hline 17 & MUJER & 82 & 81 & & GPC \\
\hline Promedios & M: $88,23 \% \quad H: 11,76 \%$ & $83,92 / 100$ & $73,13 / 100$ & $74,91 / 100$ & \\
\hline
\end{tabular}

Como vemos, el desarrollo de las variables no muestra gran desbalance, al menos en la muestra, pues la diferencia más marcada en el promedio es de 13,93/100 entre la SCTR y la SLL2 como grupo, con un sector de sujetos que tienen aún problemas con el manejo de la lengua 
a traducir (20\% de los que realizaron la prueba) que no aprobó el examen Pre-TOEFL, pero, en general, no se aprecian las polarizaciones que sí están presentes en los grupos de quinto semestre, por ejemplo (Cortez, 2014).

En ningún momento se busca matizar ningún resultado, por lo que, como todo en la vida, existen muy buenos estudiantes, y otros con poco interés en su desarrollo académico. El campo de trabajo requerirá, al fin, a los mejor preparados.

\subsection{Grupo de séptimo vespertino}

En cuanto al grupo que mostró mejor SCTR, séptimo semestre vespertino (ver tabla 3), vemos una polarización de 21,94/100 entre su SCTR y la SLL2. Con respecto al "conocimiento del mundo" adquirido en preparatoria, tres y medio años atrás, solo hay una diferencia de 15,68/100 con relación a la SCTR. Por tanto, se puede apreciar que su SE es “buena”, sin tomar en cuenta su conocimiento especializado en traducción, a seis meses de egresar de la Facultad.

\section{TABLA 3}

Comparativo entre las calificaciones obtenidas de la SE, SLL2 y la subcompetencia de transferencia, que muestra una polarización de las variables en el séptimo semestre vespertino. * La alumna causó baja en el transcurso del curso. Fuente: con datos propios

\begin{tabular}{|c|c|c|c|c|c|}
\hline \multicolumn{6}{|c|}{$\begin{array}{l}\text { COMPARATIVO DE RESULTADOS ENTRE LA SUBCOMPETENCIA EXTRALINGÜISTIICA, SLL2 Y } \\
\text { LA SUBCOMPETENCIA DE TRANSFERENCIA EN SÉPTIMO SEMESTRE VESPERTINO } 2017-2\end{array}$} \\
\hline SUJETO & & SCTR & SLL2 & SE & CÓDIGO \\
\hline 1 & MUJER & 100 & 77 & 90 & ASM \\
\hline 2 & HOMBRE & 100 & 81 & 91 & MBIA \\
\hline 3 & MUJER & 98,21 & 84 & 87 & RFM \\
\hline 4 & MUJER & 98,21 & 67 & 75 & PHAM \\
\hline 5 & HOMBRE & 98,21 & 85 & 68 & RCA \\
\hline 6 & MUJER & 96,42 & NP & 85 & HBFD \\
\hline 7 & MUJER & 96,42 & 76 & 75 & TMWZ \\
\hline 8 & MUJER & 94,64 & 74 & NP & $\mathrm{OCJ} J^{*}$ \\
\hline 9 & MUJER & 92,85 & 79 & 86 & AVCZ \\
\hline 10 & MUJER & 91,07 & 75 & 67 & LAG \\
\hline 11 & HOMBRE & 87,5 & 73 & 76 & PHME \\
\hline 12 & HOMBRE & 0 & 58 & 81 & LVPC \\
\hline 13 & MUJER & NP & 57 & NP & LDK \\
\hline Promedios & H: $30,76 \%$ M: 69,23\% & $95,77 / 100$ & $73,83 / 100$ & $80,09 / 100$ & \\
\hline
\end{tabular}


Como se observa, solo tres sujetos mantuvieron un balance entre SCTR y SLL2 menor de 15/100 puntos porcentuales. De acuerdo a los datos, hay una difuminación de la competencia gramatical como tal y el conocimiento contrastivo se vuelve práctico. Es decir, son solventes al llevar a cabo un proyecto de traducción, pero su conocimiento gramatical se va perdiendo para volverse una subcompetencia contrastiva eminentemente práctica que solo detecta la forma correcta de trasladar la oración, la frase o el texto completo de L1 a L2 (cfr. Cortez, 2014).

De acuerdo a la tabla 4 (infra) hay una evolución en la activación y recuperación del "conocimiento del mundo" desde tercer semestre hasta séptimo (en unos más notorio que en otros, pero avance al fin).

Sin embargo, existe un fenómeno curioso y constante, pues en otros semestres hubo sujetos que alcanzaron calificaciones muy bajas en la SLL2 que mostraron una SCTR muy solvente (cfr. Cortez, 2014: 277). El fenómeno se repite en el séptimo semestre vespertino 2017-2.

Cabe agregar que el séptimo vespertino es un grupo competitivo y el interés por su desarrollo lo muestran sus notas sobresalientes en la mayoría de las materias. Esta variable psicológica (motivación intrínseca) no es parte de este estudio.

\section{TABLA 4}

Comparativo de la evolución de la SE entre el tercero y el séptimo semestre. Fuente: con datos propios

EVOLUCIÓN DE LA SUBCOMPETENCIA EXTRALINGÜÍSTICA DE LOS ESTUDIANTES DE

LICENCIADO EN TRADUCCIÓN

GRUPO TERCER SEMESTRE ÚNICO SÉPTIMO MATUTINO SÉPTIMO VESPERTINO

$\begin{array}{llll}\text { Subcompetencia } & 72,91 / 100 & 74,91 / 100 & 80,09 / 100\end{array}$

extralingüistica

Con relación a la percepción psicofisiológica de la tarea a realizar y postarea (cuestionarios I y II), recolectada durante los experimentos, se tratará en la revisión de la subcompetencia respectiva, una vez que se procesen los datos.

El presente estudio nos deja una pregunta de trabajo interesante: ¿Acaso el balance mostrado en las variables por el séptimo semestre matutino muestra un asentamiento y cimentación de la CT holística? Para ello se debe buscar la posible existencia de algún patrón en otros grupos similares en un periodo de tiempo significativo.

\section{Conclusiones}

Con relación a los resultados en la SE, vemos que el bagaje de conocimientos que les permitió a los sujetos examinados acceder al nivel superior de educación sigue vigente y se incre- 
menta al paso de los semestres. El nivel mostrado desde el tercer al séptimo semestre va de "regular" a "bueno" (72,91-80,09/100), y evoluciona de manera patente.

La SCTR presenta un rango de 83,92-95,77/100, lo que es "bueno" y "muy bueno" para un producto casi terminado y a seis meses de egresar. Sin embargo, en la SLL2 existen deficiencias, al grado de que cinco sujetos no aprobaron el examen Pre-TOEFL. El rango alcanzado va de 73,13-73,83/100, lo que habla de un rango "regular" en la lengua a traducir. Aunque los sujetos a diario conviven con lectoescritura en inglés debido a los proyectos de traducción (incluso en la traducción de una página web), y redactan hacia su lengua materna, el 73,83/100 en SLL2 de promedio en ambos grupos de séptimo semestre nos dice que no hay unanimidad en la práctica de las habilidades de la lengua a traducir, y que la comprensión auditiva y producción oral se dejan de lado en la práctica (a menos que el grupo elija materias de interpretación). Ese desbalance nos muestra un fenómeno digno de estudiarse, y para ello se deben buscar baremos que puedan dar cuenta real del mismo. Dentro del análisis de los datos visualizamos líneas favorables a su desarrollo y zonas de oportunidad para mejorar lo anterior, tales como promover intercambios más expeditos y efectivos de alumnos con universidades de EE. UU. en la región, donde "vivan" inmersos en el idioma y lo practiquen por un semestre o un año, siempre atendiendo el objetivo de elevar la calidad de los alumnos a egresar. Otra propuesta es que el idioma a traducir se integre al plan de estudios como materia obligatoria. Finalmente, que las materias (salvo las de español) sean impartidas en inglés para evitar que los sujetos pierdan el interés en la producción oral y en cultivar el estudio del idioma de trabajo.

\section{Bibliografía citada}

Ausubel, David, Joseph Donald Novak y Helen Hanesian, 1976 [1968]: Psicología educativa, un punto de vista cognoscitivo, México: Trillas.

BeLL, Roger, 1991: Translation and Translating, Londres: Longman.

Chinoy, Ely, 2002 [1960]: Introducción a la sociología. Conceptos básicos y aplicaciones, México, D.F.: Paidós.

Colina, Sonia, 2009: "Further evidence for a functionalist approach to translation quality evaluation", Target 21 (2), 235-264.

Cortez, José, 2015: "Control de calidad y competencia traductora”, Plurilinkgua 11 (1), 33-49.

Cortez, José, 2014: El nivel socioeconómico de los estudiantes de traducción en la Facultad de Idiomas-Mexicali de la UABC, como variable condicionante en la adquisición de la competencia traductora: Un estudio exploratorio. Tesis de doctorado, Universidad de Granada en España. 
Cortez, José, Israel Figueroa y Nancy Luna, 2013: "Competencia traductora y subcompetencia tecnológica” en Celina García y Luis Juan Solis (comps.): Literacidad y Traducción, Estado de México: Universidad Autónoma del Estado de México, 85-111.

Cortez, José, Kora Basich e Israel Figueroa, 2012: "Competencia Traductora vs. Subcompetencia tecnológica: El caso Facultad de Idiomas Mexicali” en Memorias del XIII Encuentro Nacional de Estudios en Lenguas, Universidad Autónoma de Tlaxcala, Facultad de Filosofía y Letras, 222-248.

Cortez, José, Kora Basich e Israel FigueroA, 2015: "Subcompetencia Instrumental, vital en la formación de traductores” en Martha Beltrán, Gabriel Garduño, Carmen Gómez-Pezuela, Anna Sokolova y Lucrecia Monleón (coords.): Visiones y perspectivas en torno al estudio de las lenguas extranjeras en diversos contextos de México, Encuentro Pedagógico de Lenguas en la Educación Profesional: Teorías y prácticas de la didáctica de lenguas, México, D.F.: UAMX, 89-104.

Barceló, Tanagua, e Iván Delgado, 2017: "Análisis de las subcompetencias lingüística, extralingüística e instrumental en el proceso de enseñanza-aprendizaje de la traducción jurídica y económica (francés-español) a partir de una experiencia docente”, Sendebar 28 (31), 31-51.

GILE, Daniel, 1995: Basic Concepts and Models for Interpreter and Translator Training, Amsterdam/Philadelphia: John Benjamins.

Guajardo, Ana Gabriela, 2013: Modelo Multifuncional de la evaluación de la traducción. Tesis doctoral, Universidad de Granada [recuperado de https://goo.gl/6WYSte].

Hansen, Gyde, 2003: "Controlling the process: Theoretical and methodological reflections on research into translation processes" en Favio Alves (ed.): Triangulating Translation: Perspectives in Process Oriented Research, Amsterdam: John Benjamins, 25-42.

HARRIS, Albert, y Edward SIPAY, 1990: How to increase reading ability: A guide to developmental \& remedial methods, gth ed., New York: Longman.

Hatım, Basil, 2001: Teaching and Researching Translation, Longman: England.

Kelly, Dorothy, 2002: "Un modelo de competencia traductora: bases para el diseño curricular", Puentes: hacia nuevas investigaciones en la mediación intercultural 1, 9-20.

KIRALY, Donald, 2000: A Social Constructivist Approach to Translator Education, Manchester: St. Jerome.

Mayoral Asensio, Roberto, 1997: "La traducción especializada como operación de documentación”, Sendebar 8-9, 137-153. 
Martinez, Manuel, Julia Martinez y Visitación Calzado, 2006: "La Competencia Cultural como referente de la Diversidad Humana en la Prestación de Servicios y la Intervención Social”, Intervención Psicosocial 15 (3), 331-350.

Meersohn, Cynthia, 2005: "Introducción a Teun van Dijk: análisis de discurso", Cinta de Moebio, Revista de Epistemología de Ciencias Sociales 24, 288-302.

Moura, Marcia, y Lincoln Fernandes, 2016: "Integrating translation theory with task-based activities”, Linguagem \& Ensino, Pelotas 19 (2), 9-31.

NIDA, Eugene, y Charles TABER, 1969: The theory and practice of translation, Leiden: E. J. Brill.

PACTE, 2000: "Acquiring Translation Competence: Hypotheses and Methodological Problems in a Research Project" en Allison Beeby, Doris Ensinger y Marisa Presas (eds.): Investigating Translation, Amsterdam: John Benjamins, 99-106.

PACTE, 2001: “La competencia traductora y su adquisición”, Quaderns. Revista de Traducció 6, 39-45.

PACTE, 2002: "Grupo PACTE: una investigación empírico-experimental sobre la adquisición de la competencia traductora” en Amparo Alcina Caudet y Silvia Gamero Pérez (eds.): La traducción científico-técnica y la terminología en la sociedad de la información, Castellón de la Plana: Publicacions Universitat Jaume I, 125-138.

PACTE, 2003: "Building a Translation Competence Model” en Fabio Alves (ed.): Triangulating Translation: Perspectives in Process Oriented Research, Amsterdam: John Benjamins, 43-66.

PACTE, 2005: "Investigating Translation Competence: Conceptual and Methodological Issues", META 50/2, 609-619.

PACTE, 2008: "First results of a Translation Competence Experiment: 'Knowledge of Translation' and 'Efficacy of the Translation Process'” en John Kearns (ed.): Translator and Interpreter Training. Issues, Methods and Debates, London: Continuum, 104-126.

PACTE, 2009: "Results of the Validation of the PACTE Translation Competence Model: Acceptability and Decision Making”, Across Languages and Cultures 10 (2), 207-230.

PACTE, 2011: "Results of the Validation of the PACTE Translation Competence Model: TransIation Project and Dynamic Translation Index" en Sharon O'Brien (ed.): IATIS Yearbook 2010, Londres: Continuum, 30-53.

PARICIO, Silvina, 2014: "Competencia intercultural en la enseñanza de lenguas extranjeras", Porta Linguarum 21, 215-226. 
Pozo, Juan Ignacio, 2006: Teorías Cognitivas del Aprendizaje, Editorial Morata: España.

QuezadA, Camilo, 2004: “Comprensión lectora y traducción”, Onomázein (9) 1, 105-119.

SCHÄFfner, Christina, 2000: "Running before walking? designing a translation programme at undergraduate level” en Christina ScHÄFfner y Beverly AdAB (eds.): Developing Translation Competence, Birmingham: Benjamins, 143-156.

Valderrey, Cristina, 2005: “¿Cómo ser un traductor jurídico competente? De la competencia temática" en María Elena García, Antonio Gonzalez, Claudia Kunschak y Patricia Scarampi (eds.): Actas de las IV Jornadas Internacionales sobre la Formación y la Profesión del Traductor e Intérprete: Calidad y Traducción. Perspectivas académicas y profesionales, Madrid: Universidad Europea de Madrid Ediciones.

VAn DIJk, Teun Adrianus, 1980: Estructuras y funciones del discurso, Madrid: Ediciones Siglo XXI. VAn Dıık, Teun Adrianus, 2012: Discurso y contexto. Un enfoque sociocognitivo, Gedisa: Barcelona.

\section{Anexos}

\section{Anexo 1. Baremo utilizado para la evaluación de las traducciones en 2017-2}

Baremo adaptado de Colina (2009), originalmente con 100 ítems a medir. Fuente: Guajardo (2013)

\section{ESCALA DE EVALUACION}

En el siguiente formato se utiliza una escala de 1 a 4, en la que el mayor puntaje corresponde a una buena traducción:

1 (muchos errores) 2 (algunos errores) 3 (mínimos errores) 4 (ningún error)

\section{EVALUACIÓN DE LOS ASPECTOS LINGÜÍSTICOS, LÉXICOS Y DEL PROCESO DE TRADUCCIÓN}

\begin{tabular}{|c|c|c|c|c|}
\hline a. Concordancia en género y en número & $1 \square$ & $2 \square$ & $3 \square$ & $4 \square$ \\
\hline b. Cohesión y coherencia de los tiempos verbales & $1 \square$ & $2 \square$ & $3 \square$ & $4 \square$ \\
\hline c. Utilización de terminología apropiada & $1 \square$ & $2 \square$ & $3 \square$ & $4 \square$ \\
\hline d. Adecuación del registro del texto & $1 \square$ & $2 \square$ & $3 \square$ & $4 \square$ \\
\hline e. Puntuación & $1 \square$ & $2 \square$ & $3 \square$ & $4 \square$ \\
\hline
\end{tabular}




\begin{tabular}{|c|c|c|c|c|}
\hline f. Ortografía (acentos, mayúsculas, etc.) & $1 \square$ & $2 \square$ & $3 \square$ & $4 \square$ \\
\hline g. Adaptaciones culturales (siglas, expresiones, etc.) & $1 \square$ & $2 \square$ & $3 \square$ & $4 \square$ \\
\hline h. Contra sentidos & $1 \square$ & $2 \square$ & $3 \square$ & $4 \square$ \\
\hline i. Falsos sentidos & $1 \square$ & $2 \square$ & $3 \square$ & $4 \square$ \\
\hline j. Sin sentidos & $1 \square$ & $2 \square$ & $3 \square$ & $4 \square$ \\
\hline k. Omisión injustificada & $1 \square$ & $2 \square$ & $3 \square$ & $4 \square$ \\
\hline I. Adición injustificada & $1 \square$ & $2 \square$ & $3 \square$ & $4 \square$ \\
\hline m. Evidencia de una revisión minuciosa & $1 \square$ & $2 \square$ & $3 \square$ & $4 \square$ \\
\hline n. Reproducción del formato original & $1 \square$ & $2 \square$ & $3 \square$ & $4 \square$ \\
\hline
\end{tabular}

Total: 156

\section{Anexo 2. Resultados de la subcompetencia extralingüística en tercer semes-} tre 2017-2

El gráfico muestra los resultados del grupo de tercer semestre en la medición de la subcompetencia extralingüística, que en promedio alcanzó 72.91/100. Lo anterior nos lleva a ubicarla en el rango de regular. Los sujetos en rojo son de sexo masculino, que representa el 25\% del grupo. Fuente: con datos propios

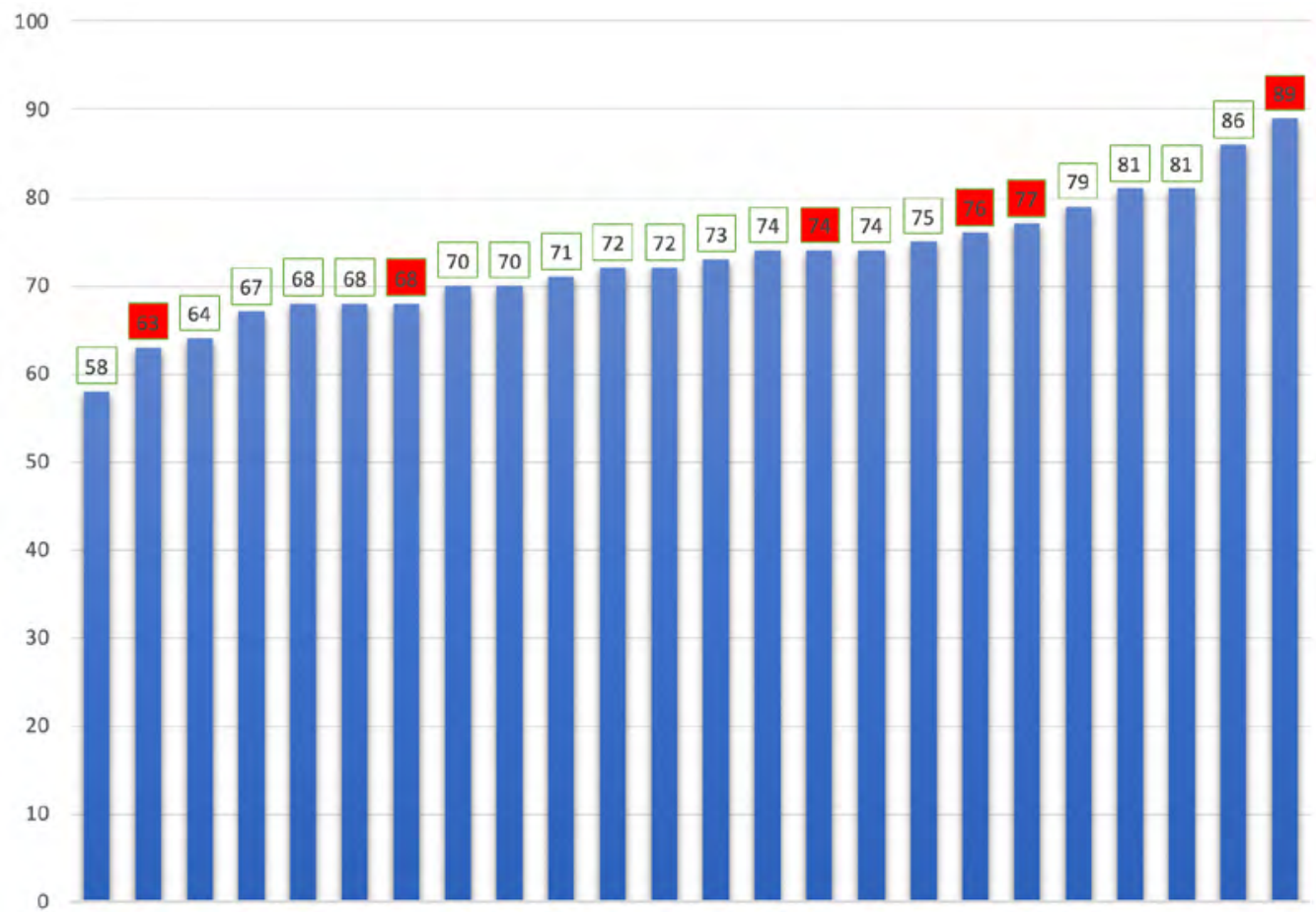




\section{Anexo 3. Subcompetencia extralingüística en séptimo semestre matutino 2017-2}

Calificaciones de SE en $7 .^{\circ}$ semestre matutino por sexo.

Doce sujetos, de un grupo de 17 se sometieron a la medición de la SE en el séptimo semestre matutino de la Licenciatura en Traducción. Lo anterior equivale al 70,58\% del universo medido. Fuente: Con datos propios

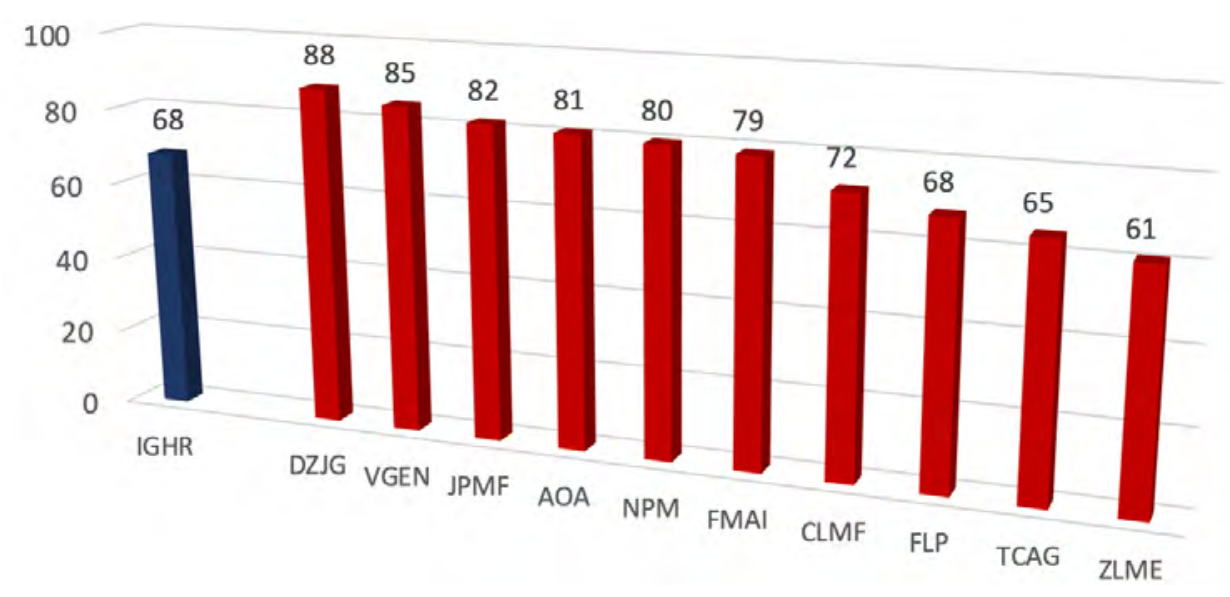

\section{Anexo 4. Subcompetencia extralingüística en séptimo semestre vespertino 2017-2}

Calificaciones de SE en $7 .^{\circ}$ semestre vespertino por sexo.

Trece sujetos participaron en la medición de la SE en el séptimo semestre vespertino de la Licenciatura en Traducción. Lo anterior representa el 100\% del grupo en esa variable. Fuente: Con datos propios

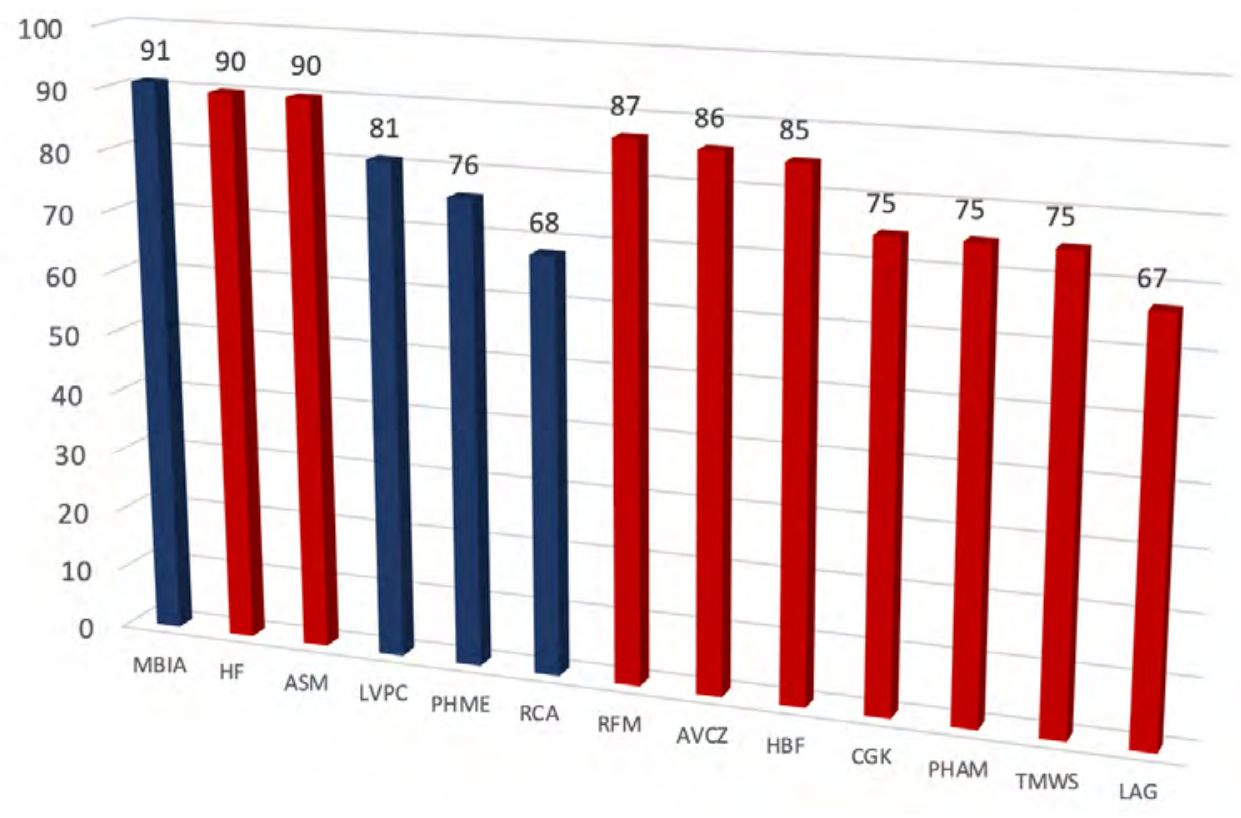


Anexo 5. Detalle del examen de conocimiento enciclopédico

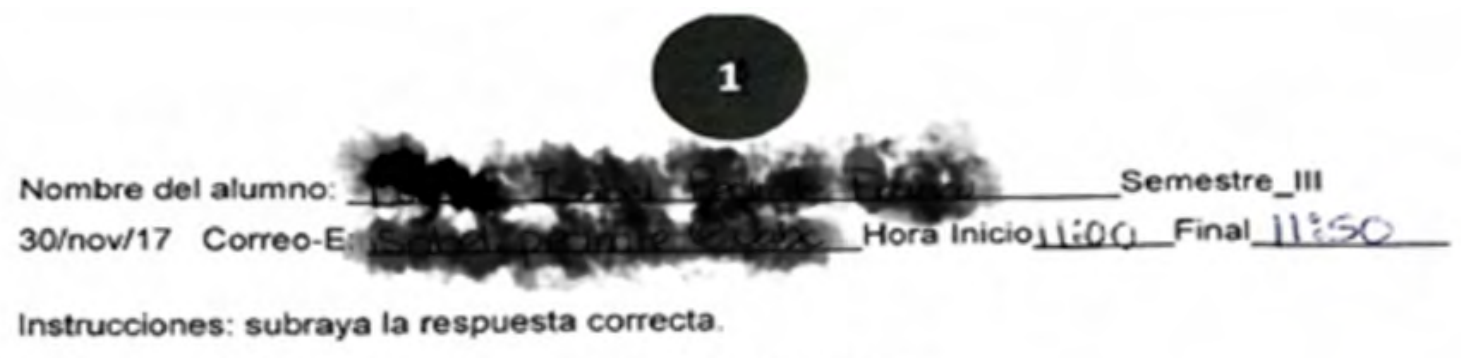

\section{Lectura y redacción}

1. Sistema de comunicación estructurado para el que existe un contexto de uso y ciertos principios combinatorios formales.
A) Lenquale
B) Platicar
C) Lengua
D) Lingüistica

2. Sistema de comunicación verbal y escrito, de convenciones y reglas gramaticales, empleado por las comunidades humanas con fines comunicativos. Usualmente, está basada en símbolos sonoros, pero también puede estar constituida únicamente por signos gráficos.
A) Lenguaje
B) Lengua
C) Hablar
D) Linguistica

3. Es la parte de la oración que recibe de manera indirecta la acción del verbo
A) Objeto Directo
B) Articulos
c) Objeto indirecto
D) Adjetivos

4. Parte de la oración que recibe de manera directa y en primer lugar la acción del verbo. Recibe la acción de un verbo transitivo
A) Objeto directo
B) Verbo
C) Objeto indirecto
D) Artículos

5. Palabra que contiene un prefijo.
A) Silla
B) Altanero
C) Ampl amente
D) Microcosmos

6. Enseñanza que se obtiene de una historia, cuento, fábula, narración, anécoota, etc
A) Moraleja
B) Fábula
C) Historia
D) Cuento

7. Breve narración o historia que contiene una moraleja.
A) Historia
B) Fábula
C) Cuento
D) Noticia

8. Completa la oración de manera correcta: No fui a la fiesta no tenia ganas.
A) Por qué
B) Porqué
C) Porque
D) Sino

9. Ella le la comida a los cerdos.
A) Écho
B) Hechó
C) Echó
D) Echo

10. ¿Cuál de estas frases es correcta?
A) Habian muchas personas en la sala.
B) Ha habido algunas quejas.
C) Los invitados se ha ido temprano.
D) Hubo problemas parafintrar al concerto.

11. Estoy seguro me va a salir bien este examen. 


\section{Anexo 5 b. Muestra de las áreas que aborda el examen de conocimiento en- ciclopédico}

Nombre del alumno:

Fecha: Semestre

Instrucciones: subraya la respuesta correcta.

\section{Lectura y redacción}

1. Sistema de comunicación estructurado para el que existe un contexto de uso y ciertos principios combinatorios formales.
A) Lenguaje
B) Platicar
C) Lengua
D) Lingüística

3. Es la parte de la oración que recibe de manera indirecta la acción del verbo.
A) Objeto Directo
B) Articulos
C) Objeto indirecto
D) Adjetivos

\section{Historia}

32. ¿Quién fue el primer presidente de México?
A) Gugdalupe Victoria
B) Agustín de lturbide
C) Benito Juárez
D) Porfirio Díaz

33. ¿En qué año Miguel Hidalgo y Costilla da el grito de Independencia?
A) 1810
B) 1800
C) 1910
D) 1811

40. Científico que formuló la teoria de la evolución.
A) Charles Darwin
B) Galileo Galilei
C) Louis Pasteur
D) Isasc Newton

Salud

43. A tu hermana que está casada, el médico le recomendó utilizar pildoras anticonceptivas, este es un método anticonceptivo de tipo:
A) Hormonal o químico
B) De barrera
C) Definitivo
D) Mecánico

\section{Biología}

María tiene una gatita que tuvo cinco gatitos, dos negros, uno blanco con negro, uno blanco y uno negro de patas blancas.

51. ¿A qué diversidad crees que correspondan las diferencias en los gatitos?
A) Poblacional
B) Especie
C) Genética
D) Biológica

59. 4.-Es uno de los organismos en peligro de extinción de Baja California:
A) Vacas
B) Sahuaros
C) Borrego cimarrón
D) Biznagas

64. En décadas pasadas en el Golfo de Baja California se observó que una especie estaba en peligro de extinción, debido a la captura inmoderads, a que especie se refiere:
A) Borrego cimarrón
B) Vaquita marina
C) Alondra
D) Ardillas gris mexicana 


\section{Química}

69. Reacción química que se produce entre el oxígeno y un material oxidable, que va acompañada de desprendimiento de energía y habitusimente se manifiesta por incandescencia o llama.
A) Combustión
B) Separación
C) Evaporación
C) Mezcla

\section{Estructura socioeconómica}

76. Es la sgrupación de diversos individuos organizados sin la participación del Estado, por ejemplo: asociaciones culturales, clubes, organizaciones de sectores de la sociedad como los grupos de homosexusles, mujeres, empresarios, ecologistas, etc.
A) Sociedsd politica
B) Sociedad económica
C) Sociedad civil
D) Sociedad

\section{Métodos de investigación}

94. En la consulta de diferentes biografías de un personaje histónico y en la revisión de fuentes como: periódicos, revistas y películas, ¿qué tipo de investigación realizamos?
A) Experimental
B) De campo
C) Documental
D) Cientifica

Final del documento

\section{Anexo 6. Protocolo Previo de Traducción}

Metodología para la evaluación de la subcompetencia de transferencia de los estudiantes de la Licenciatura en Traducción (Fuente: Cortez, 2015)

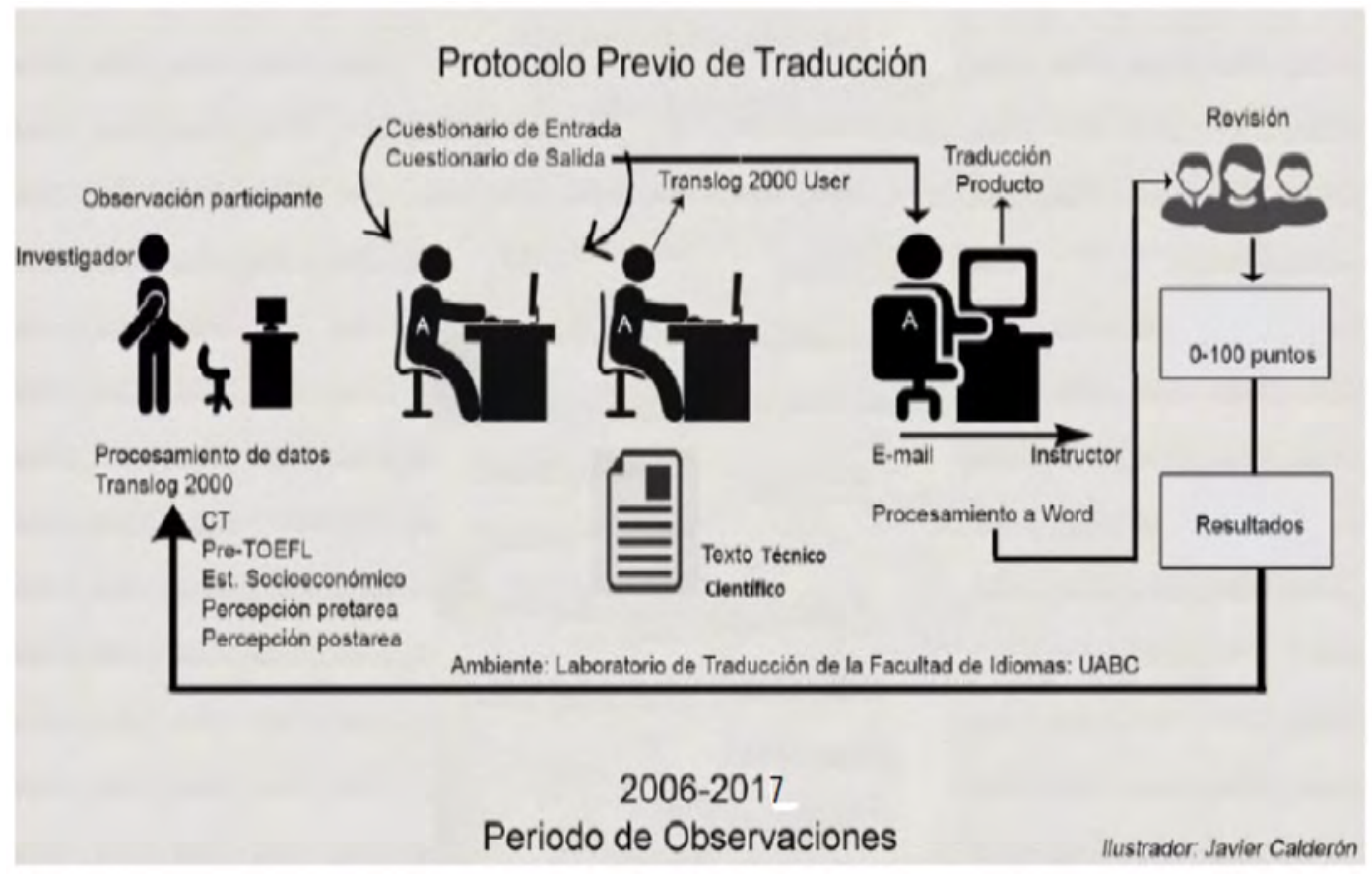




\section{Anexo 7. Original de traducción "Short-sightedness" en el programa Translog-} 2000user

國 ELC Translog - User - TEXTO MIOPIAstp

File Edit About

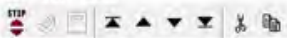

Shat tighedear

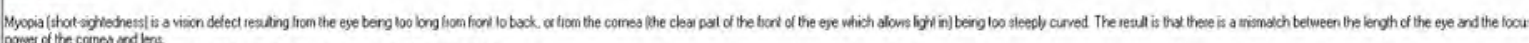
Donere of the connes ond lent

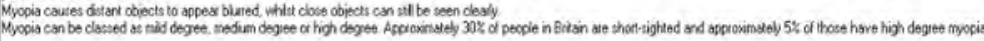

Symploms

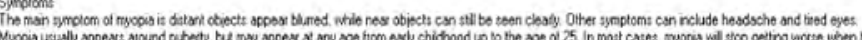

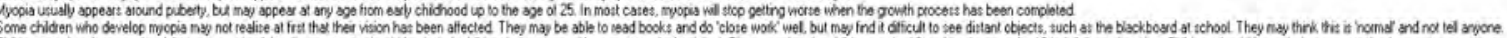

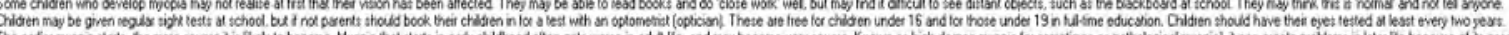

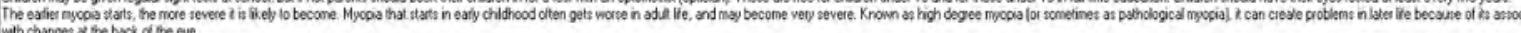

Canes

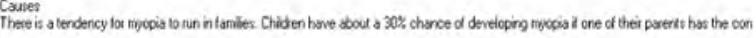

Diagnoni

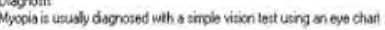

Tiesment

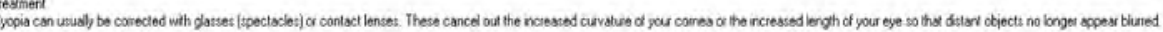

\section{Anexo 7 b. Ejemplo de texto traducido con espacios y errores ortotipográficos}

Miopía

La $\square$ miopía $\square$ es $\square$ un $\square$ defecto $\square$ de $\square$ la $\square$ visión $\square$ que $\square$ ocurre $\square$ cuando $\square$ el $\square$ ojo $\square$ es $\square$ muy $\square$ largo, $\square$ o $\square$ cornea $\square$ (la $\square$ partede $\square$ enfrente $\square$ del $\square$ ojo $\square$ que $\square$ permite $\square$ que $\square$ entre $\square$ la $\square$ luz) $\square$ esta $\square$ abr uptamente $\square \square$ curveada. $\square$ El $\square$ resulto $\square$ es $\square$ que nohay $\square$ coordinación $\square$ entre $\square$ el $\square$ largo $\square$ del $\square$ o jo $\square$ y $\square$ el $\square$ enfoque $\square$ de $\square$ la $\square$ córnea $\square$ y $\square$ lentes. $\square$ La $\square$ miopía $\square$ puede $\square \square$ causar $\square$ que $\square$ los $\square$ obj etos $\square$ en $\square$ la $\square$ lejania $\square$ se $\square$ vean $\square$ borrosos, $\square$ mientras $\square$ los $\square$ objetos $\square$ cercanos $\square$ se $\square$ ven $\square$ con $\square$ claridad. $\square$ Puede $\square$ ser $\square$ de $\square$ un $\square$ grado $\square$ leve, $\square$ moderado $\square$ o $\square$ alto, $\square$ aproximadamente $\square$ el $\square$ 30\& $\square$ de $\square$ la $\square$ población $\square$ de $\square$ Gran $\square$ Bretaña $\square$ padece $\square$ de $\square$ vista $\square$ cirta $\square$ y $\square$ otro $\square$ aproximand o $\square$ del $\square 5 \% \square$ padecen $\square$ de $\square$ miopía $\square$ grave.

\section{Síntomas}

Los principales síntomas son: los objetos distantes $\square$ se $\square$ ven $\square$ borrosos, $\square$ mientras $\square$ los $\square$ c ercanos $\square$ se $\square$ ven $\square$ con $\square$ claridad, $\square$ otro síntoma $\square$ inlcuye $\square$ dolores $\square$ de $\square$ cabeza $\square$ y $\square$ ojos $\square$ c ansados.

Suele $\square$ aparecer $\square$ alrededor $\square$ de $\square$ la $\square$ pubertad, $\square$ pero $\square$ tambien $\square$ puede $\square$ aparecer $\square \mathrm{a} \square$ cualq uier $\square$ edad $\square$ desde $\square$ la $\square$ infancia hasta $\square$ los $\square 25 \square$ años $\square$ de $\square$ edad. $\square$ En $\square$ muchos $\square$ casos, $\square$ la $\square$ miopía $\square$ dejará $\square$ de $\square$ empeorar una $\square$ vez $\square \square$ se $\square$ termine $\square$ de $\square$ crecer.

Algunos $\square$ niños $\square$ que $\square$ lo $\square$ desarrollan $\square$ puede $\square$ que $\square$ no $\square$ se $\square$ den $\square$ cuenta $\square$ que $\square$ su $\square$ visión $\square$ a $\square$ sido $\square$ afectada, pueden $\square$ leer $\square$ libros $\square$ y $\square$ hacer $\square$ trabajo $\square$ cercano $\square$ (como $\square$ estar $\square$ enfoca do $\square$ en $\square$ un $\square$ libro), $\square$ pero puede $\square$ que $\square$ se les $\square$ dificulte $\square$ ver $\square$ objetos $\square$ distantes $\square$ como: $\square$ los pizarrones $\square$ en $\square$ las $\square$ escuelas. $\square$ Puede $\square$ que $\square$ piensen $\square$ que $\square$ es $\square$ "normal $\square$ y $\square$ no $\square$ le $\square$ digan 
$\square \mathrm{a} \square$ nadie. $\square$ Pueden $\square$ recibir $\square$ exámenes $\square$ de $\square$ la $\square$ vista $\square$ en $\square$ sus $\square$ escuelas, $\square$ pero $\square$ en $\square \square$ d ado $\square$ caso $\square$ de $\square$ que $\square$ no, $\square$ los $\square$ padres $\square$ deben $\square$ hacer $\square$ una $\square$ cita $\square$ con $\square$ un $\square$ optometrista $\square$ ( óptico), $\square$ son $\square$ gratis $\square \square$ para $\square$ niños $\square$ menores $\square$ de $\square$ 16 $\square$ años $\square$ y $\square$ para $\square$ aquellos $\square$ menores $\square$ a $\square 19 \square$ años $\square$ en $\square$ escuelas $\square$ de $\square$ tiempo $\square \square$ completo, $\square$ se $\square$ recomienda $\square$ que $\square$ hagan $\square$ un $\square$ e xámen $\square$ de $\square$ la $\square$ vista $\square$ al $\square$ menos $\square$ dos $\square$ veces $\square$ al $\square$ año. Si $\square$ la $\square$ miopía $\square$ empieza $\square \mathrm{a} \square$ una $\square$ e dad $\square$ temprana, $\square$ es más probable que $\square$ se $\square$ vuelva $\square$ severa. $\square$ Si $\square$ empieza $\square$ en $\square$ la $\square$ infancia, $\square$ esta $\square$ suele $\square$ empeorar $\square$ en $\square$ la $\square$ adultez, $\square$ conocida $\square \square \square$ como $\square$ miopía $\square$ de $\square$ alto $\square$ grado $\square$ ( a $\square$ veces $\square$ conocida $\square$ como $\square$ miopía $\square$ patológica). $\square$ Puede $\square$ crear $\square$ problemas $\square \mathrm{a} \square$ lola $\square$ larga $\square$ debido $\square \mathrm{a} \square$ su $\square$ asociación $\square$ con $\square$ los $\square$ cambios $\square$ en $\square$ la $\square$ aprte $\square$ trasera $\square$ del $\square$ ojo.

Causas

Puede ser hereditario, se tiene un $30 \%$ de posibilidades de padecerla si uno de los padres lo padece.

\section{Diagnóstico}

Se puede diagnosticar con un simple exámen de la vista.

Tratamiento

Se $\square$ puede $\square$ corregir $\square$ con $\square$ lentes $\square$ o $\square$ lentes $\square$ de $\square$ contacto $\square$ (pupilentes), $\square$ estos $\square$ cancelan $\square$ la $\square$ curvatura $\square$ en $\square$ la $\square \square$ córnea $\square$ o $\square$ incrementa $\square$ el $\square$ largo $\square$ de $\square$ tu $\square$ ojo $\square$ para $\square$ los $\square$ objetos $\square$ distantes $\square$ no $\square$ se $\square$ vean $\square$ borrosos. SGA 